\title{
REPETIBILIDADE E CORRELAÇÕES ENTRE CARACTERES MORFO-AGRONÔMICOS DE CAJAZEIRA
}

\section{Repeatability and correlations among yellow mombim morphoagronomical traits}

\author{
Edson Basílio Soares ${ }^{1}$, Regina Lucia Ferreira Gomes², José Elivalto Guimarães Campelo ${ }^{3}$, \\ Ângela Celis de Almeida Lopes ${ }^{4}$, Carlos Humberto Aires Matos Filho ${ }^{5}$
}

\begin{abstract}
RESUMO
Objetivou-se estimar os coeficientes de repetibilidade em quatorze cajazeiras (Spondias mombin L.), no município de Teresina, PI, utilizando-se o método de análise de variância; determinar o número de medições necessárias para predição do valor real dos indivíduos e os coeficientes de correlação fenotípica entre os caracteres: comprimento e largura da folha, número de folíolos por folha, peso da panícula, número de frutos por panícula, comprimento, diâmetro e peso do fruto, peso da semente, rendimento de polpa, teor de sólidos solúveis, acidez titulável, relação sólidos solúveis/acidez. Os genótipos diferiram com relação a todos os caracteres avaliados, indicando a presença de variabilidade genética. As estimativas dos coeficientes de repetibilidade expressaram maior estabilidade para peso do fruto, diâmetro do fruto, peso da semente, acidez titulável e relação sólidos solúveis/acidez titulável, indicando maior precisão na predição do valor real desses caracteres, nas cajazeiras. A avaliação de onze frutos é suficiente para predizer o valor real de todos os caracteres, com $90 \%$ de confiabilidade. A seleção para maior produtividade de frutos pode ser alcançada através da seleção indireta para caracteres relacionados à folha. Panícula mais pesada pode ser obtida pela seleção indireta de genótipos com sementes de menor peso.
\end{abstract}

Termos para indexação: Spondias mombin, cajá, parâmetros genéticos, qualidade de fruto.

\begin{abstract}
The objective of this work was to estimate the coefficient of repeatability in fourteen yellow mombim (Spondias mombin L.), in Teresina, Piauí State, through the variance analysis method, in order to determine the number of measures necessary for an accurate prediction of the real genotype value and the correlation coefficients among the leaf length, leaf width, number of leaflets for leaf, panicles weight, number of fruits for panicles, fruit length, fruit diameter, fruit weight, seed weight, pulp revenue, soluble solid (SS), titrable acidity (AT) and SS/AT ratio. The genotypes had significant differences in all traits, indicating the existence of genetic variability. The estimates of the coefficients of repeatability expressed a greater stability for fruit weight, fruit diameter, seed weight, titrable acidity and soluble solid/titrable acidity ratio, indicating more accuracy to the real value pediction of these yellow mombim traits. The evaluation of eleven fruits is enough to predict the real value of all characters with an accuracy of $90 \%$. The selection for characters related to the leaf could lead to an indirect selection for high fruit yield. The high panicle weight could be selected through the indirect selection for low seed weight.
\end{abstract}

Index terms: Spondias mombin, yellow mombim, genetic parameters, fruit quality.

(Recebido em 2 de outubro de 2007 e aprovado em 10 de junho de 2008)

\section{INTRODUÇÃO}

A cajazeira (Spondias mombin L.) é uma árvore frutífera nativa da América Tropical, pertencente à família Anacardiaceae, cujo gênero inclui espécies como cirigueleira, cajaraneira, umbuzeira, umbucajazeira e umbugueleira. No Brasil, encontra-se dispersa nas regiões Norte e Nordeste, sendo considerada uma espécie em domesticação que ainda não é cultivada comercialmente, mas que já participa de sistemas de produção extrativistas (SACRAMENTO \& SOUZA, 2000).

A expansão do cultivo de cajazeiras em escalas ou modelos comerciais requer o uso de material propagativo proveniente de genótipos com elevado potencial produtivo e caracteres desejáveis (BOSCO et al., 2000).

O ciclo longo e a grande área requerida para o desenvolvimento de plantas perenes inibem a instalação de campos para seleção de genótipos superiores utilizando

\footnotetext{
'Engenheiro Agrônomo, Mestre - Departamento de Fitotecnia/DF - Centro de Ciências Agrárias/CCA - Universidade Federal do Piauí/UFPI - Campus Ministro Petrônio Portela - Ininga - 64049-550 - Teresina, PI - edbasoares@ig.com.br

${ }^{2}$ Engenheira Agrônoma, Doutora - Departamento de Fitotecnia/DF - Centro de Ciências Agrárias/CCA - Universidade Federal do Piauí/UFPI - Campus Ministro Petrônio Portela - Ininga - 64049-550 - Teresina, PI - rlfgomes@ufpi.edu.br

${ }^{3}$ Engenheiro Agrônomo, Doutor - Departamento de Zootecnia - Centro de Ciências Agrárias/CCA - Universidade Federal do Piauí/UFPI - Campus Ministro Petrônio Portela - Ininga -64049-550 - Teresina, PI - elivalto@ufpi.br

${ }^{4}$ Engenheira Agrônoma, Doutora - Departamento de Biologia - Centro de Ciências Agrárias/CCA - Universidade Federal do Piauí/UFPI - Campus Ministro Petrônio Portela - Ininga - 64049-550 - Teresina, PI - acalopes@ufpi.br

${ }^{5}$ Engenheiro Agrônomo, Mestre - Departamento de Planejamento e Política Agrícola/DPPA - Centro de Ciências Agrárias/CCA - Universidade Federal do Piauí/UFPI - Campus Ministro Petrônio Portela - Ininga - 64049-550 - Teresina, PI - carumba@ig.com.br
} 
delineamentos estatísticos adequados. Isso dificulta a estimativa de parâmetros genéticos, tais como a herdabilidade, indispensável na orientação dos programas de melhoramento genético (ALBUQUERQUE et al., 2004).

$\mathrm{Na}$ seleção de um genótipo superior, espera-se que persistam pelas gerações seguintes, as suas características iniciais desejáveis. A veracidade dessa expectativa pode ser comprovada pelo coeficiente de repetibilidade, definido como sendo a correlação entre medidas ou avaliações realizadas em um mesmo indivíduo, no tempo ou no espaço (CRUZ et al., 2004). O coeficiente de repetibilidade expressa a proporção da variância total que é de origem genética e aquelas causadas pelo ambiente permanente. Representa o limite superior da herdabilidade e permite estimar o número de observações necessárias para cada caráter, num determinado indivíduo, proporcionando maior eficiência na seleção com um mínimo de mão-de-obra e custo (FALCONER, 1987) sem muita sofisticação experimental (ALBUQUERQUE et al., 2004). Esse coeficiente também tem sido estimado em parâmetros de estabilidade (FARIAS et al., 1998), de grande importância para os melhoristas, nos quais nem sempre é possível estimar a herdabilidade.

Diversos trabalhos têm sido desenvolvidos com plantas perenes, utilizando estimativas de repetibilidade, para seleção de genótipos superiores, podendo-se destacar: seringueira (VASCONCELOS et al., 1985), cupuaçuzeiro (COSTA et al., 1997), cajueiro-anão-precoce (CAVALCANTI et al., 2000), aceroleira (LOPES et al., 2001), bacurizeiro (FARIAS NETO et al., 2004; MULLER et al., 2002; SOUSA et al., 2001), açaizeiro (OLIVEIRA \& FERNANDES, 2001), goiabeira-serrana (DEGENHARDT et al., 2002), pupunheira (FARIAS NETO et al., 2002), mangueira (COSTA, 2003) e pessegueiro (ALBUQUERQUE et al., 2004).

Objetivou-se estimar os coeficientes de repetibilidade para caracteres morfo-agronômicos de cajazeiras, determinar o número mínimo de avaliações necessárias em um indivíduo para se ter confiabilidade nas inferências realizadas e estimar os coeficientes de correlação entre caracteres, visando a seleção de matrizes superiores de cajazeira.

\section{MATERIAL E MÉTODOS}

Os quatorze genótipos nativos de cajazeira avaliados, com idade superior a oito anos, foram selecionados por apresentarem frutos de maior tamanho e sabor doce. Essas plantas localizam-se em regiões urbana e rural do município de Teresina, PI, situado a $05^{\circ} 05^{\prime}$ de latitude sul, $42^{\circ} 48^{\prime}$ de longitude oeste e $74,4 \mathrm{~m}$ de altitude.
No período de novembro a maio, época de emissão de inflorescências, desenvolvimento e maturação dos frutos, a temperatura média varia de 27,1 a $29,4{ }^{\circ} \mathrm{C}$, umidade relativa de 60,1 a $81,8 \%$ e precipitação média de $1.280 \mathrm{~mm}$ (BASTOS \& ANDRADE JÚNIOR, 2000).

Avaliaram-se os caracteres: comprimento da folha (CF), largura da folha (LF), número de folíolos por folha (NFF), número de frutos por panícula (NFP), peso da panícula (PP), peso do fruto (PFR), comprimento do fruto (CFR), diâmetro do fruto (DFR), peso da semente (PS), rendimento de polpa (RP), teor de sólidos solúveis, em ${ }^{\circ}$ Brix a $20^{\circ} \mathrm{C}$ (SS), pelo método refratométrico, acidez titulável (AT), expressa em g de ácido cítrico em $100 \mathrm{~g}$ de polpa, segundo normas do Instituto Adolfo Lutz (1985), e relação SS/AT.

A caracterização física e química dos frutos foi realizada no Núcleo de Estudos, Pesquisa e Processamento de Alimentos do Centro de Ciências Agrárias da Universidade Federal do Piauí, em frutos maduros, colhidos ao chão, pela manhã, após despolpamento manual. Foram realizadas 20 medições por caráter, em cada uma das quatorze matrizes amostradas, no período de fevereiro a maio de 2004.

As análises estatístico-genéticas foram realizadas com o auxílio do programa computacional GENES (CRUZ, 2001), utilizando-se o modelo estatístico com um fator de variação, a seguir:

$$
\gamma_{i j}=\mu+g_{i}+\varepsilon_{i j}
$$

em que:

$\gamma_{i j}$ : observação referente ao i-ésimo genótipo $(i=1,2, \ldots$, p) na j-ésima medição $\left(\mathrm{j}=1,2, \ldots, \eta_{i}\right)$;

$\mu$ : média geral;

$g_{i}$ : efeito aleatório do i-ésimo genótipo sob influência do ambiente permanente; com distribuição normal, média zero e variância s ${ }_{\mathrm{g}}{ }^{2}$;

$\varepsilon_{i j}$ : efeito do ambiente temporário associado à j-ésima medição no i-ésimo genótipo, admitido ter distribuição normal e ser independente, com média zero e variância $\mathrm{s}^{2}$.

As estimativas dos coeficientes de repetibilidade (r) foram obtidas pelo método da análise de variância, conforme a expressão a seguir (CRUZ et al., 2004):

$$
r=\operatorname{Cov}\left(Y_{i j}, Y_{i j^{\prime}}\right) \frac{\operatorname{Co} v\left(Y_{i j}, Y_{i j^{\prime}}\right)}{\sqrt{\hat{V}\left(Y_{i j}\right) \hat{V}\left(Y_{i j^{\prime}}\right)}}=\frac{\hat{\sigma}_{g}^{2}}{\hat{\sigma}_{y}^{2}}=\frac{\hat{\sigma}_{g}^{2}}{\hat{\sigma}^{2}+\hat{\sigma}_{g}^{2}}
$$

O número de medições necessárias $\left(\eta_{o}\right)$ para a predição do valor real dos indivíduos, com base no coeficiente de determinação genotípica $\left(\mathrm{R}^{2}\right)$, desejado, foi 
estimado de acordo com a expressão fornecida por Cruz et al. (2004):

$$
\eta_{o}=\frac{R^{2}(1-r)}{\left(1-R^{2}\right) r}
$$

O coeficiente de determinação genotípica $\left(\mathrm{R}^{2}\right)$, que representa a porcentagem de certeza da predição do valor real dos indivíduos selecionados, com base em $\eta$ medições foi obtido pela expressão:

$$
R^{2}=\frac{\eta r}{1+r(\eta-1)}
$$

Os coeficientes de correlação fenotípica entre os caracteres estudados foram estimados pela seguinte expressão, conforme Kempthorne (1973):

$$
r_{x y}=\frac{\operatorname{Cov}(x, y)}{\sqrt{V_{(X)} V_{(Y)}}}
$$

A significância dos coeficientes de correlação foi avaliada pela estatística t, dada por:

$t=\frac{r-p}{\sqrt{1-r^{2}}} \sqrt{n-2}$, com $\mathrm{n}-2$ graus de liberdade.

\section{RESULTADOS E DISCUSSÃO}

Os genótipos diferiram significativamente $(\mathrm{P}<0,01)$ com relação a todos os caracteres avaliados (Tabela 1). A variância genotípica entre as cajazeiras foi relativamente alta em comparação com a variância ambiental, evidenciando a existência de variabilidade genética na população em estudo, e a possibilidade de ganhos genéticos com a utilização de métodos de melhoramento simples, como a seleção massal (OLIVEIRA \& FERNANDES, 2001).

Nos caracteres peso do fruto, diâmetro do fruto, peso da semente, acidez titulável e relação sólidos solúveis/acidez titulável, as estimativas dos coeficientes de repetibilidade expressaram maior estabilidade, variando de 0,729 a 0,834 , com coeficientes de determinação $\left(\mathrm{R}^{2}\right)$ entre 98 e 99\%, indicando maior precisão na predição do valor real desses caracteres, nas cajazeiras (Tabela 2). Tais caracteres, isolados ou combinados, poderão contribuir para a identificação, seleção e propagação de indivíduos superiores. Em trabalhos realizados com bacurizeiro (MULLER et al., 2002; SOUSA et al., 2001) e aceroleira (LOPES et al., 2001), os caracteres ligados aos aspectos morfológicos dos frutos também apresentaram coeficientes de repetibilidade com elevadas magnitudes $(\mathrm{h}>0,70)$.

Para comprimento da folha, largura da folha, número de folíolos por folha, número de frutos por panícula, peso da panícula, comprimento do fruto, rendimento de polpa e teor de sólidos solúveis, cujos coeficientes de repetibilidade variaram de 0,447 a 0,661 , a predição do valor real dos genótipos foi menos precisa, com $\mathrm{R}^{2}$ em torno de 94 a $97 \%$ (Tabela 2), indicando que esses caracteres foram mais influenciados pelos efeitos ambientais, e que a seleção indireta, via caracteres de melhor controle genético, seria uma estratégia interessante a ser aplicada.

Tabela 1 - Quadrados médios obtidos nas análises de variância dos caracteres: comprimento da folha, largura da folha, número de folíolos por folha, número de frutos por panícula, peso da panícula, peso do fruto, comprimento do fruto, diâmetro do fruto, peso da semente, rendimento de polpa, teor de sólidos solúveis, acidez titulável e relação sólidos solúveis/acidez titulável, avaliados em matrizes de cajazeira, em Teresina, PI, 2004.

\begin{tabular}{lrrr}
\hline \multicolumn{1}{c}{ Caracteres } & \multicolumn{2}{c}{ Fontes de variação } & Média geral \\
\cline { 2 - 3 } & Entre genótipos $^{1}$ & Dentro de genótipos $^{2}$ & \\
\hline Comprimento da folha (cm) & $1.874,61^{* *}$ & 100,52 & 50,58 \\
Largura da folha (cm) & $282,59 * *$ & 10,68 & 25,31 \\
Número de folíolos por folha & $124,92^{* *}$ & 5,11 & 17,46 \\
Número de frutos por panícula & $12.566,81^{* *}$ & 328,20 & 30,33 \\
Peso da panícula (g) & $630.750,39^{* *}$ & $20.511,31$ & 270,29 \\
Peso do fruto (g) & $179,39 * *$ & 2,90 & 9,91 \\
Comprimento do fruto (mm) & $197,61^{* *}$ & 4,93 & 33,73 \\
Diâmetro do fruto (mm) & $189,70^{* *}$ & 3,45 & 23,54 \\
Peso da semente (g) & $14,37 * *$ & 0,24 & 2,71 \\
Rendimento de polpa (\%) & $96,84^{* *}$ & 5,64 & 72,60 \\
Teor de sólidos solúveis ( ${ }^{\circ}$ Brix) & $35,91^{* *}$ & 0,96 & 4,08 \\
Acidez titulável (\% de ácido cítrico) & $6,69 * *$ & 0,65 & 1,56 \\
Relação sólidos solúveis/acidez titulável & $331,69^{* *}$ & 3,51 & 10,51 \\
\hline
\end{tabular}

${ }^{1} \mathrm{GL}=13 ;{ }^{2} \mathrm{GL}=266 ; * *$ Significativo pelo teste $\mathrm{F}(\mathrm{P}<0,01)$. 
Tabela 2 - Estimativas dos coeficientes de repetibilidade $(\widehat{\tau})$, coeficientes de determinação $\left(\mathrm{R}^{2}\right)$ e do número de medições calculados $\left(\eta_{o}\right)$, utilizando o método da análise de variância, para os caracteres: comprimento da folha, largura da folha, número de folíolos por folha, número de frutos por panícula, peso da panícula, peso do fruto, comprimento do fruto, diâmetro do fruto, peso da semente, rendimento de polpa, teor de sólidos solúveis, acidez titulável e relação sólidos solúveis/acidez, avaliados em matrizes de cajazeira, em Teresina, PI, 2004.

\begin{tabular}{|c|c|c|c|c|c|}
\hline \multirow[t]{2}{*}{ Caracteres } & \multicolumn{2}{|c|}{$\begin{array}{l}\text { Valor obtido a partir } \\
\text { de } 20 \text { medições }\end{array}$} & \multicolumn{3}{|c|}{$\begin{array}{c}\text { Número de medições necessárias para } \\
\text { diferentes coeficientes de determinação }\left(\mathrm{R}^{2}\right)\end{array}$} \\
\hline & $\hat{\tau}$ & $\mathrm{R}^{2}(\%)$ & $\mathrm{R}^{2}$ & & $\eta_{o}$ \\
\hline \multirow[t]{3}{*}{ Comprimento da folha $(\mathrm{cm})$} & 0,468 & 94,60 & 0,90 & 10 & $(10,20)$ \\
\hline & & & 0,95 & 22 & $(21,53)$ \\
\hline & & & 0,99 & 112 & $(112,19)$ \\
\hline \multirow[t]{3}{*}{ Largura da folha $(\mathrm{cm})$} & 0,559 & 96,20 & 0,90 & 7 & $(7,08)$ \\
\hline & & & 0,95 & 15 & $(14,94)$ \\
\hline & & & 0,99 & 78 & $(77,82)$ \\
\hline \multirow[t]{3}{*}{ Número de folíolos por folha } & 0,539 & 95,90 & 0,90 & 8 & $(7,69)$ \\
\hline & & & 0,95 & 16 & $(16,24)$ \\
\hline & & & 0,99 & 85 & $(84,60)$ \\
\hline \multirow{3}{*}{ Número de frutos por panícula } & 0,651 & 97,30 & 0,90 & 5 & $(4,83)$ \\
\hline & & & 0,95 & 10 & $(10,19)$ \\
\hline & & & 0,99 & 53 & $(53,10)$ \\
\hline \multirow[t]{3}{*}{ Peso da panícula (g) } & 0,598 & 96,70 & 0,90 & 6 & $(6,05)$ \\
\hline & & & 0,95 & 13 & $(12,77)$ \\
\hline & & & 0,99 & 67 & $(66,55)$ \\
\hline \multirow[t]{3}{*}{ Peso do fruto $(\mathrm{g})$} & 0,752 & 98,30 & 0,90 & 3 & $(2,96)$ \\
\hline & & & 0,95 & 6 & $(6,26)$ \\
\hline & & & 0,99 & 33 & $(32,60)$ \\
\hline \multirow[t]{3}{*}{ Comprimento do fruto $(\mathrm{mm})$} & 0,661 & 97,50 & 0,90 & 5 & $(4,65)$ \\
\hline & & & 0,95 & 10 & $(9,70)$ \\
\hline & & & 0,99 & 51 & $(50,60)$ \\
\hline \multirow[t]{3}{*}{ Diâmetro do fruto (mm) } & 0,729 & 98,10 & 0,90 & 3 & $(3,34)$ \\
\hline & & & 0,95 & 7 & $(7,05)$ \\
\hline & & & 0,99 & 37 & $(36,74)$ \\
\hline \multirow[t]{3}{*}{ Peso da semente $(\mathrm{g})$} & 0,741 & 98,2 & 0,90 & 3 & $(3,14)$ \\
\hline & & & 0,95 & 7 & $(6,62)$ \\
\hline & & & 0,99 & 35 & $(34,51)$ \\
\hline \multirow[t]{3}{*}{ Rendimento de polpa (\%) } & 0,447 & 94,10 & 0,90 & 11 & $(11,14)$ \\
\hline & & & 0,95 & 24 & $(23,51)$ \\
\hline & & & 0,99 & 122 & $(122,48$ \\
\hline \multirow[t]{3}{*}{ Teor de sólidos solúveis $\left({ }^{\circ}\right.$ Brix $)$} & 0,644 & 97,30 & 0,90 & 5 & $(4,97)$ \\
\hline & & & 0,95 & 11 & $(10,50)$ \\
\hline & & & 0,99 & 55 & $(54,71)$ \\
\hline \multirow[t]{3}{*}{ Acidez titulável (\% de ácido cítrico) } & 0,834 & 99,00 & 0,90 & 2 & $(1,78)$ \\
\hline & & & 0,95 & 4 & $(3,76)$ \\
\hline & & & 0,99 & 20 & $(19,61)$ \\
\hline \multirow[t]{3}{*}{ Relação sólidos solúveis/acidez titulável } & 0,824 & 98,90 & 0,90 & 2 & $(1,92)$ \\
\hline & & & 0,95 & 4 & $(4,05)$ \\
\hline & & & 0,99 & 21 & $(21,13)$ \\
\hline
\end{tabular}


A avaliação de onze frutos é suficiente para predizer o valor real de todos os caracteres, com $90 \%$ de confiabilidade (Tabela 2). Para seleção de genótipos com 95\% de determinação do valor real, o número de medições determinado como necessário, variou de 4 a 16, tamanho amostral inferior ao utilizado no presente trabalho, exceto para comprimento da folha e rendimento de polpa, que necessitam de 22 e 24 medições, respectivamente. Maior nível de precisão pode requerer amostras muito maiores e aumentar os custos (OLIVEIRA \& FERNANDES, 2001), o que dificulta o processo de avaliação. Muller et al. (2002), trabalhando com bacurizeiros, consideraram impraticável a avaliação de caracteres que necessitam de mais de 114 medições para alcançar $99 \%$ de determinação do valor real dos indivíduos.

Os caracteres relacionados ao comprimento e largura da folha e número de folíolos por folha apresentaram correlações significativas e positivas com peso da panícula
(Tabela 3). O número de folíolos por folha também se correlacionou positiva e significativamente com número de frutos por panícula. Esses resultados indicam que o número de folíolos por folha poderá ser utilizado na seleção indireta de plantas com maior número de frutos por panícula e panículas mais pesadas, caracteres desejáveis no melhoramento genético da cajazeira.

Entre peso do fruto, comprimento do fruto, diâmetro do fruto e peso da semente, as correlações foram positivas, com magnitudes variando de 0,60 a 0,97 , indicando que alterações no tamanho do fruto, afetam os demais caracteres no mesmo sentido. Para o mercado de polpas, o ideal é a ocorrência de correlações negativas entre peso da semente com os demais caracteres, porque permite a seleção de genótipos com maior rendimento de polpa. A seleção de genótipos com sementes de menor peso, caráter desejável, pode ser obtida pela seleção indireta para maior peso da panícula.

Tabela 3 - Estimativas das correlações fenotípicas entre os caracteres: comprimento da folha (CF), largura da folha (LF), número de folíolos por folha (NFF), número de frutos por panícula (NFP), peso da panícula (PP), peso do fruto (PFR), comprimento do fruto (CFR), diâmetro do fruto (DFR), peso da semente (PS), rendimento de polpa (RP), teor de sólidos solúveis (SS), acidez titulável (AT), relação sólidos solúveis/acidez titulável (SS/AT), avaliados em matrizes de cajazeira, em Teresina, PI, 2004.

\begin{tabular}{|c|c|c|c|c|c|c|c|c|c|c|c|c|}
\hline Caracteres & LF & $\mathrm{NFF}$ & NFP & PP & PFR & CFR & DFR & PS & $\mathrm{RP}$ & SS & $\mathrm{AT}$ & SS/AT \\
\hline $\mathrm{CF}$ & $0,844 * *$ & $0,687 *$ & 0,354 & $0,639 *$ & 0,300 & 0,482 & 0,399 & 0,246 & $-0,199$ & $-0,108$ & $-0,450$ & 0,580 \\
\hline $\mathrm{LF}$ & & 0,460 & 0,392 & $0,647^{*}$ & 0,097 & 0,437 & 0,255 & 0,624 & $-0,177$ & 0,227 & 0,544 & 0,648 \\
\hline $\mathrm{NFF}$ & & & $0,765^{* *}$ & $0,775^{* *}$ & $-0,063$ & 0,338 & $-0,155$ & $-0,102$ & $-0,189$ & $-0,101$ & $-0,033$ & 0,171 \\
\hline NFP & & & & $0,879 * *$ & $-0,435$ & 0,103 & 0,449 & $-0,449$ & 0,138 & 0,078 & 0,224 & $-0,103$ \\
\hline PP & & & & & $-0,044$ & 0,428 & 0,038 & $-0,858^{*}=$ & $-0,189$ & 0,150 & 0,714 & 0,211 \\
\hline PFR & & & & & & $0,766^{* *}$ & $0,899 * *$ & $0,965^{* *}$ & $-0,033$ & 0,065 & $-0,306$ & 0,338 \\
\hline CFR & & & & & & & $0,604 *$ & $0,746 * *$ & $-0,043$ & 0,398 & $-0,347$ & 0,439 \\
\hline DFR & & & & & & & & $0,871 * *$ & $-0,022$ & $-0,066$ & $-0,233$ & 0,275 \\
\hline PS & & & & & & & & & 0,225 & $-0,147$ & $-0,238$ & 0,271 \\
\hline RSF & & & & & & & & & & $-0,312$ & 0,196 & $-0,191$ \\
\hline SS & & & & & & & & & & & 0,378 & 0,410 \\
\hline AT & & & & & & & & & & & & $-0,968^{*}$ \\
\hline SS/AT & & & & & & & & & & & & \\
\hline
\end{tabular}

* e **: Significativos a 5\% e $1 \%$ de probabilidade, respectivamente, pelo teste $\mathrm{t}$. 


\section{CONCLUSÕES}

A ocorrência de variabilidade genética entre as genótipos avaliados indica a possibilidade de seleção de plantas superiores.

A seleção baseada em quatro a sete medições dos caracteres peso do fruto, diâmetro do fruto, peso da semente, acidez titulável e relação sólidos solúveis/acidez titulável, permite predizer o valor real dos indivíduos com nível de certeza de 0,95 , indicando a eficiência da seleção massal para esses caracteres. Com onze medições, o valor real de todos os caracteres é predito com $90 \%$ de confiabilidade.

Genótipos com panículas mais pesadas e maior número de frutos podem ser selecionados através do número de folíolos por folha.

\section{REFERÊNCIAS BIBLIOGRÁFICAS}

ALBUQUERQUE, A. S.; BRUCKNER, C. H.; CRUZ, C. D.; SALOMÃO, L. C. C.; NEVES, J. C. L. Repeatability and correlations among peach physical traits. Crop Breeding and Applied Biotechnology, Londrina,v. 4, n. 4, p. 441-445, Dec. 2004

BASTOS, E. A.; ANDRADE JUNIOR, A. S. Dados agrometeorológicos para o município de Teresina, PI (1980 - 1999). Teresina: Embrapa Meio-Norte, 2000. 25 p. (Documentos, 47).

BOSCO, J.; SOARES, K. T.; AGUIAR FILHO, S. P.; BARROS, R. V. A cultura da cajazeira. João Pessoa: EMEPA, 2000. 229 p. (Documentos, 28).

CAVALCANTI, J. J. V.; PAIVA, J. R.; BARROS, L. M.; CRISÓSTOMO, J. R.; CORREAA, M. P. F. Repetibilidade de caracteres de produção e porte da planta em clones de cajueiro-anão-precoce. Pesquisa Agropecuária Brasileira, Brasília, v. 35, n. 4, p. 773-777, abr. 2000.

COSTA, J. G. Estimativas de repetibilidade de alguns caracteres de produção em mangueiras. Ciência Rural, Santa Maria, v. 33, n. 2, p. 263-266, mar./abr. 2003.

COSTA, J. G.; LEDO, A. S.; OLIVEIRA, M. N. Estimativas de repetibilidade de características de frutos de cupuaçuzeiro no Estado do Acre. Revista Brasileira de Fruticultura, Cruz das Almas, v. 19, n. 3, p. 313-318, 1997.

CRUZ, C. D. Programa Genes: versão windows: aplicativo computacional em genética e estatística. Viçosa: UFV, 2001. $648 \mathrm{p}$.
CRUZ, C. D.; REGAZZI, A. J.; CARNEIRO, P. C. S. Modelos biométricos aplicados ao melhoramento genético. Viçosa: UFV, 2004. 480 p.

DEGENHARDT, J.; DUCROQUET, J. P.; REIS, M. S.; GUERRA, M. P.; NODARI, R. O. Efeito de anos e determinação do coeficiente de repetibilidade de características de frutos de goiabeira-serrana. Pesquisa Agropecuária Brasileira, Brasília, v. 37, n. 9, p. 1285-1293, set. 2002.

FALCONER, D. S. Introdução à genética quantitativa. Viçosa: UFV, 1987. 279 p.

FARIAS, F. J. C.; RAMALHO, M. A. P.; CARVALHO, L. P.; MOREIRA, J. A. N.; COSTA, J. N. Repetibilidade dos parâmetros de estabilidade na cultura do algodoeiro herbáceo. Pesquisa Agropecuária Brasileira, Brasília, v. 33, n. 4, p. 457-461, abr. 1998.

FARIAS NETO, J. T.; CARVALHO, J. U.; MULLER, C. H. Estimativas de correlação e repetibilidade para caracteres do fruto de bacurizeiro. Ciência e Agrotecnologia, Lavras, v. 28 , n. 2, p. 302-307, mar./abr. 2004.

FARIAS NETO, J. T.; YOKOMIZO, G.; BIANCHETTI, A. Coeficientes de repetibilidade genética de caracteres em pupunheira. Revista Brasileira de Fruticultura, Jaboticabal, v. 24, n. 3, p. 731-733, dez. 2002.

INSTITUTO ADOLFO LUTZ. Normas analíticas do Instituto Adolfo Lutz. 3. ed. São Paulo: IMESP, 1985. 553 p.

KEMPTHORNE, O. An introduction to genetics statistics. Ames: Iowa State University, 1973. 545 p.

LOPES, R.; BRUCKNER, C. H.; CRUZ, D. C.; LOPES, M. T. G.; FREITAS, G. B. Repetibilidade de características do fruto de aceroleira. Pesquisa Agropecuária Brasileira, Brasília, v. 36, n. 3, p. 507-513, mar. 2001.

MULLER, C. H.; FARIAS NETO, J. T.; CARVALHO, J. E. U. Estimativas dos coeficientes de repetibilidade para caracteres do fruto do bacurizeiro (Platonia insignis Mart). In: CONGRESSO BRASILEIRO DE FRUTICULTURA, 17. 2002, Belém. Anais... Belém: SBF, 2002. CD-ROM.

OLIVEIRA, M. S. P.; FERNANDES, G. L. C. Repetibilidade de caracteres do cacho de açaizeiro nas condições de Belém, PA. Revista Brasileira de Fruticultura, Jaboticabal, v. 23, n. 3, p. 613-616, dez. 2001. 
SACRAMENTO, C. K.; SOUZA, F. X. Cajá (Spondias mombin L.). Jaboticabal: FUNEP, 2000. 42 p. (Frutas nativas).

SOUSA, V. A. B.; ARAÚJO, E. C. E.; VASCONCELOS, L. F. L. Variabilidade de características físicas e químicas de frutos de germoplasma de bacuri da região Meio-Norte do
Brasil. Revista Brasileira de Fruticultura, Jaboticabal, v. 23, n. 3 , p. 677-683, dez. 2001.

VASCONCELOS, M. E. C.; GONÇALVES, P. S.; PAIVA, J. R.; VALOIS, A. C. C. Métodos de estimação do coeficiente de repetibilidade da seringueira. Pesquisa Agropecuária Brasileira, Brasília, v. 20, n. 4, p. 433-437, abr. 1985. 